\title{
Unveiling microscopic carrier loss mechanisms in $12 \%$ efficient Cu2ZnSnSe4 solar cells
}

\author{
Jianjun Li \\ University of New South Wales (UNSW) https://orcid.org/0000-0003-2872-9648 \\ Jialiang Huang \\ UNSW https://orcid.org/0000-0002-8954-7680
}

\section{Fa-jun Ma}

UNSW Australia

\section{Heng Sun}

UNSW Sydney

Jialin Cong

UNSW Sydney

Karen Privat

UNSW Sydney

Yin Yao

UNSW Sydney

Robert Chin

UNSW Sydney

Mingrui He

UNSW Sydney

\section{Kaiwen Sun}

UNSW Sydney https://orcid.org/0000-0001-5589-226X

\section{Hui Li}

Chinese Academy of Sciences

\section{Yaohua Mai}

Jinan University

\section{Ziv Hameiri}

Univerity of New South Wales

\section{Ned Ekins-Daukes}

UNSW Sydney https://orcid.org/0000-0003-1875-9739

\section{Richard Tilley}

UNSW Sydney https://orcid.org/0000-0003-2097-063X

\section{Thomas Unold}

Helmholtz-Zentrum Berlin für Materialien und Energie https://orcid.org/0000-0002-5750-0693

\section{Martin Green}


University of New South Wales https://orcid.org/0000-0002-8860-396X

\section{Xiaojing Hao ( $\nabla$ xj.hao@unsw.edu.au )}

UNSW https://orcid.org/0000-0001-5903-4481

\section{Article}

Keywords:

Posted Date: February 9th, 2022

DOI: https://doi.org/10.21203/rs.3.rs-1274090/v1

License: (c) (i) This work is licensed under a Creative Commons Attribution 4.0 International License. Read Full License

Version of Record: A version of this preprint was published at Nature Energy on July 21 st, 2022. See the published version at https://doi.org/10.1038/s41560-022-01078-7. 


\title{
Unveiling microscopic carrier loss mechanisms in $12 \%$ efficient $\mathrm{Cu}_{2} \mathrm{ZnSnSe} 4$ solar cells
}

Jianjun Li ${ }^{a \# *}$, Jialiang Huang ${ }^{a \#,}$, Fajun Ma ${ }^{a \#,}$, Heng Sun ${ }^{a}$, Jialin Cong ${ }^{a}$, Karen Privat ${ }^{b}$, Yin Yao ${ }^{b}$, Robert Lee Chin ${ }^{a}$, Mingrui He ${ }^{a}$, Kaiwen Sun ${ }^{a}$,Hui Li ${ }^{c}$, Yaohua Mai ${ }^{d}$,Ziv Hameiri ${ }^{a}$, Nicholas J. Ekins-Daukes ${ }^{a}$, Richard D. Tilley ${ }^{b}$, Thomas Unold ${ }^{e}$, Martin A. Green ${ }^{a}$, Xiaojing Hao ${ }^{a *}$

a Australian Centre for Advanced Photovoltaics, School of Photovoltaic and Renewable Energy Engineering, University of New South Wales, Sydney, NSW 2052, Australia.

${ }^{\mathrm{b}}$ Electron Microscope Unit, Mark Wainwright Analytical Centre, University of New South Wales, Sydney, NSW 2052, Australia.

${ }^{\mathrm{c}}$ Beijing National Laboratory for Condensed Matter Physics, Institute of Physics, Chinese Academy of Sciences, Beijing 100190, China

${ }^{\mathrm{d}}$ Institute of New Energy Technology, College of Information Science and Technology, Jinan University, Guangzhou 510632, China.

${ }^{\mathrm{e}}$ Helmholtz-Zentrum für Materialien und Energie, Hahn-Meitner-Platz 1, 14109 Berlin, Germany

\# J.L. J.H. and F.M. contributed equally.

*Correspondence should be addressed to J.L. (jianjun.li@unsw.edu.au) or X.H. (xj.hao@unsw.edu.au)

\begin{abstract}
Carrier loss mechanisms at microscopic regions is imperative for high-performance polycrystalline inorganic thin-film solar cells. Despite the progress on Kesterite, a promising environmental-benign and earth-abundant thin-film photovoltaic material, the microscopic carrier loss mechanisms and their impact on device performance remain unknown. Herein, we unveil these mechanisms in state-of-the-art $\mathrm{Cu}_{2} \mathrm{ZnSnSe}_{4}$ (CZTSe) solar cells using a framework that links microscopic-structural and optoelectronic characterizations with three-dimensional device simulations. The results indicate the CZTSe films have an encouraging intragrain minority carrier lifetime of $>10 \mathrm{~ns}$, a marginal radiative recombination loss
\end{abstract}


through sub-band recombination and electrostatic potential fluctuation, whilst a large effective grain boundary recombination velocity of around $10^{4} \mathrm{~cm} \mathrm{~s}^{-1}$ and a low net carrier density of $\sim 1 \times 10^{15} \mathrm{~cm}^{-3}$. We identify that severe grain boundary recombination and low net carrier density are the current limiting factors of device performance. The established framework can greatly advance the research of kesterite and other emerging photovoltaic materials.

\section{Introduction}

Photovoltaics have been identified as the most attractive renewable energy that can be used to mitigate the escalating global climate change. ${ }^{1}$ Large scale deployments of photovoltaic energy require stable, abundant, and low-toxic materials similar to silicon $(\mathrm{Si}),{ }^{2}$ which has stimulated the worldwide interest in new inorganic photovoltaic materials such as chalcogenides, oxides, pnictides, and halides. ${ }^{3-6}$ Kesterite $\mathrm{Cu}_{2} \mathrm{ZnSn}(\mathrm{S}, \mathrm{Se})_{4}$ (CZTSSe) has emerged as one of the most compelling candidates due to its stable structure, abundancy, environmental benefits, and its large potential for high power conversion efficiency (PCE). ${ }^{7,8}$ Although, CZTSSe solar cells have reached the highest PCE (12.6\% to $\left.13.0 \%\right)$ among the thermodynamically stable emerging inorganic materials, ${ }^{9-11}$ their PCE is still far from a commercialization-viable level.

To allow low-cost processing, CZTSSe like many other emerging inorganic solar cells, often uses polycrystalline thin-films as light absorbers and follows the heterojunction architecture. ${ }^{4}$ This device architecture accommodates a significant amount of imperfect crystalline structures, mainly grain boundaries (GBs) and grain surfaces. At these regions, dangling bonds, elastic strain fields, and atomic composition segregations may introduce electronic states within the energy bandgap with higher density than that in the grain interiors (GIs). ${ }^{12}$ These bandgap states may act as carrier traps and/or effective recombination centers depending on their transition energy level and relative capture cross-section for 
holes and electrons, thus, imposing serious limitations to the minority carrier lifetime and carrier mobilities. ${ }^{13}$ Consequently, the photovoltaic performance of polycrystalline absorbers is usually inferior to that of crystalline absorbers ${ }^{14,15}$, unless the grain boundaries and grain surfaces are electrical-benign, like the case of hybrid halide perovskite ${ }^{16}$, or can be well passivated such as in the cases of CdTe and $\mathrm{CuInGa}(\mathrm{S}, \mathrm{Se})_{2}(\mathrm{CIGSSe})^{17-20}$. Therefore, understanding the carrier loss mechanisms at these microscopic regions is imperative for achieving high-performance CZTSSe and other emerging inorganic thin-film solar cells.

Despite the critical importance of these microscopic carrier loss mechanisms in inorganic materials, the number of investigations regarding these processes is rather limited. For CZTSSe, due to the multiple competitive secondary phases and complex intrinsic defect system, ${ }^{21}$ most efforts have been paid to the bulk and heterojunction interfaces, through modifications of the chemical composition and growth conditions, ${ }^{22-25}$ extrinsic cation/alkali doping or alloying, ${ }^{7,26,27}$ alternative buffer materials, ${ }^{28,}{ }^{29}$ or interface passivation. ${ }^{30-32}$ Although some properties of the GIs and GBs such as intragrain crystallinity defects and band bending at the GBs have been investigated using high-resolution structural and electrical analysis respectively, ${ }^{33}, 34$ detailed loss mechanisms in these microscopic regions especially GB recombination and grain interior carrier lifetime, and their impact on the device performance remain unknown. This, as a critical gap between the understanding of CZTSSe and its mature cousins CdTe and CIGSSe, can be one of the key origins of the efficiency stagnation of CZTSSe in recent years, thus requiring comprehensive investigation urgently.

Herein, we unveil the microscopic carrier loss mechanisms in state-of-the-art efficiency selenide-kesterite $\mathrm{Cu}_{2} \mathrm{ZnSnSe}_{4}$ (CZTSe) solar cells by establishing a framework that links micro-structural and optoelectronic characterizations with three-dimensional (3D) device simulations. We show that the GB recombination limits the effective carrier lifetime of bulk kesterite. The associated GB recombination 
velocity of kesterite, at a level of $10^{4} \mathrm{~cm} \mathrm{~s}^{-1}$, is 1-2 orders of magnitude larger than that of CIGSSe and CdTe. ${ }^{35}{ }^{36}$ The intragrain minority carrier lifetime is estimated to be $>10 \mathrm{~ns}$ while the net carrier density is around $1 \times 10^{15} \mathrm{~cm}^{-3}$. It seems that the well-recognized open-circuit voltage (Voc) losses due to electrostatic potential fluctuation and bandgap fluctuation are actually small. Instead, the dominating loss mechanisms of current state-of-the-art CZTSe solar cells are associated with the severe non-radiative recombination at GBs and the relatively low net carrier density.

\section{Results}

\section{Photovoltaic performance and absorber structure}

We used CZTSe absorbers fabricated by the same method used for our reported $12.5 \%$ record CZTSe cells. ${ }^{22}$ Details of the fabrication processes can be found in the Methods section. The solar cells fabricated on these absorbers achieve PCEs between $11.0 \%$ to $12.5 \%$ and an average PCE of 11.8\% (Figure S1), representing state-of-the-art performance. Figure 1a and $\mathbf{1 b}$ show the current density-voltage (J-V) and external quantum efficiency (EQE) of one of the best devices used for characterizations in this study. The total area $\left(0.24 \mathrm{~cm}^{2}\right)$ efficiency is $12.45 \%$, with a $\mathrm{V}_{\mathrm{OC}}$ of $479 \mathrm{mV}$, a fill factor (FF) of $70.45 \%$, and a short-circuit current density $\left(\mathrm{J}_{\mathrm{SC}}\right.$ ) of $36.9 \mathrm{~mA} / \mathrm{cm}^{2}$ (integrated $\mathrm{J}_{\mathrm{SC}}$ from EQE is $37.0 \mathrm{~mA} / \mathrm{cm}^{2}$ ). The diode ideality factor $(A)$ extracted from corresponding dark J-V data is 1.4 and the diode reverse saturation current $\left(\mathrm{J}_{0}\right)$ is $8.1 \times 10^{-8} \mathrm{~A} / \mathrm{cm}^{2}$ (Figure $\mathbf{S 2}$ ). The $\mathrm{J}_{\mathrm{SC}}$ is much lower than the previous $11.6 \%$ efficiency record CZTSe device from IBM $\left(40.6 \mathrm{~mA} / \mathrm{cm}^{2}\right),{ }^{37}$ which could be attributed to the relatively low transmittance of the window layer at the long wavelength region, as discussed in our previous work, ${ }^{22}$ and the recombination in the microscopic regions as will be discussed in the following sections.

On the top, the CZTSe absorber shows large and compact grains $(>1 \mu \mathrm{m})$ while at the bottom the grains are smaller and voids can be seen (Figure 1c). The secondary ion mass spectroscopy (SIMS) depth profile 
(Figure 1d) indicates the CZTSe absorber has a high Zn concentration at the surface and high Sn concentration at the bottom. Segregations of $\mathrm{Zn}$ (probably $\mathrm{ZnSe}$ ) could be observed at both the top and the bottom of the CZTSe film in the energy-dispersive X-ray spectroscopy (EDXS) mapping (Figure 1e). Many Sn-rich small grains (probably $\mathrm{SnSe}_{\mathrm{x}}$ ) and $\mathrm{Cu}$-rich grains (probably $\mathrm{Cu}_{2-\mathrm{x}} \mathrm{Se}$ ) can be noticed at the bottom region near the $\mathrm{MoSe}_{2}$ layer, in agreement with the SIMS profile. The signal of Cd is fully confined between CZTSe and ZnO, showing no significant diffusion into the CZTSe absorber or GBs.
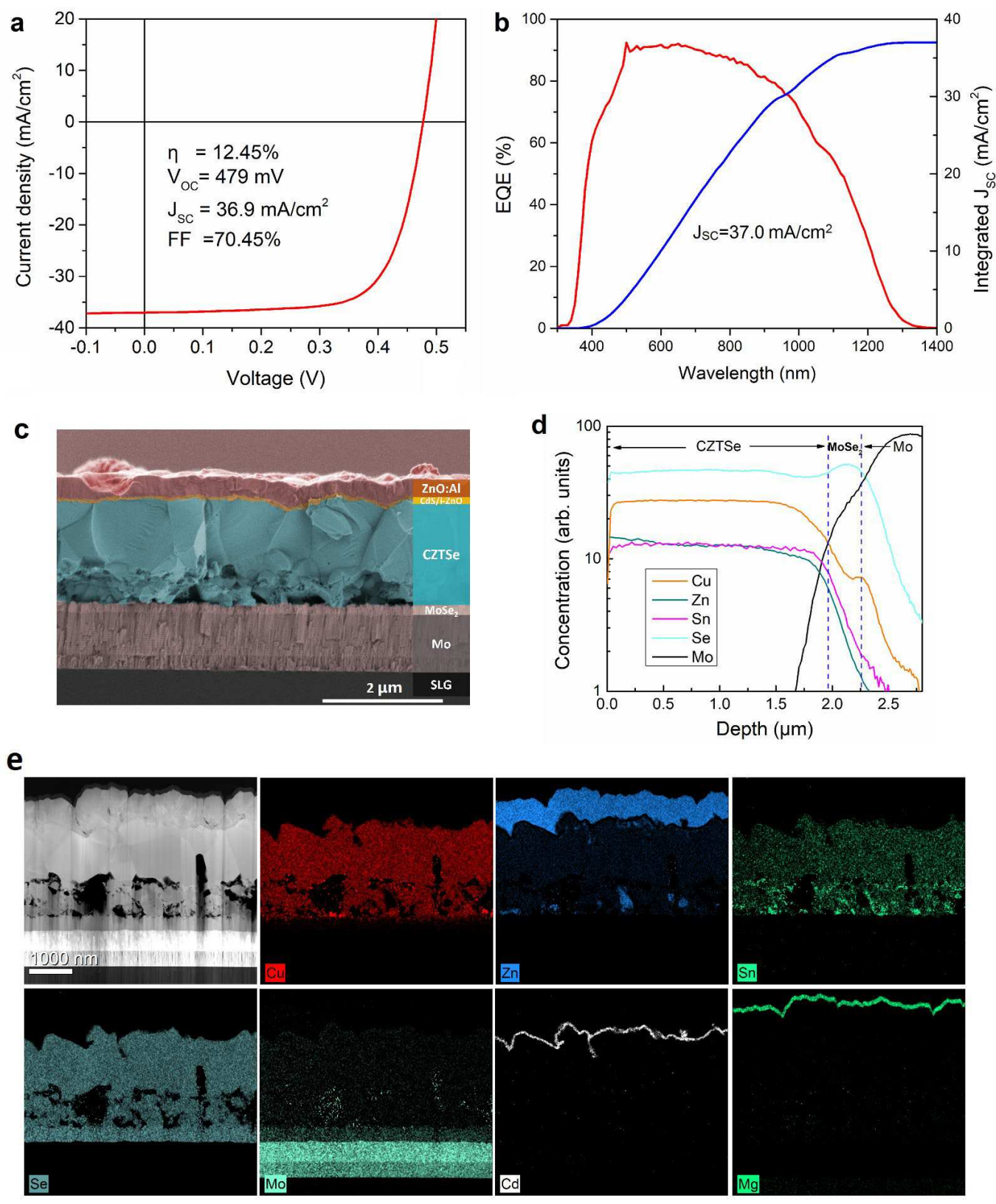
Figure 1. Device performance, morphology, and element distribution. J-V (a) and EQE (b) measurements of one of the best CZTSe cells with total area $\left(0.24 \mathrm{~cm}^{2}\right)$ efficiency of $12.45 \%$ with antireflection coating. c Cross-section SEM image. d Element SIMS depth profile of the CZTSe absorber. e The cross-section TEM image and the corresponding EDXS element mapping of $\mathrm{Cu}, \mathrm{Zn}, \mathrm{Sn}, \mathrm{Se}, \mathrm{Mo}$, $\mathrm{Cd}$, and $\mathrm{Mg}$. The cross-section TEM sample was prepared with a focused ion beam (FIB).

\section{Carrier transport at front and rear interfaces}

Results of surface Raman mapping on a $40 \times 40 \mu \mathrm{m}^{2}$ bare CZTSe absorber indicate that the front surface of the CZTSe absorber may be fully covered with a ZnSe layer (Figures 2 a-c). Further high-resolution TEM (HRTEM; Figure 2d) shows the presence of a locally epitaxially grown 8-12 nm thick ZnSe nanolayer (confirmed by EDS line-scan, Figure S3) along with the (200) orientation. With the almost identical (200) interplanar spacing between CZTSe and ZnSe $(0.283 \mathrm{~nm}$, Figure 2d), no dislocation is observed at the CZTSe/ZnSe interface, indicating a near-perfect CZTSe/ZnSe heterointerface with largely suppressed interfacial lattice defects. In comparison, the CZTSe absorber without this ZnSe nano layer shows a high density of dislocations at the CZTSe/CdS heterointerface (Figure S4). Additionally, ZnSe has a wide bandgap of $2.7 \mathrm{eV},{ }^{38}$ with a conduction band minimum (CBM) $0.86 \mathrm{eV}$ higher and a valence band maximum (VBM) $0.78 \mathrm{eV}$ lower than that of CZTSe. ${ }^{23}$ These large electron and hole barriers could repel electrons and holes respectively, preventing them from recombining at the heterojunction interface, i.e., effectively suppressing interfacial recombination. On the other hand, due to the large "spike-like" conduction band offset $(\mathrm{CBO}, 0.86 \mathrm{eV})$ at the $\mathrm{ZnSe} / \mathrm{CZTSe}$ interface, transport of the photogenerated electrons across this interface may rely on the tunnelling process with the assistance of the built-in electric field and thermal energy. It is noted that a continuous ZnSe layer with 8-12 nm thickness may block the electron current as tunneling would be very difficult under this condition. Fortunately, in the large scale, the thickness of ZnSe nano layer has a significant fluctuation as indicated by the varying $\mathrm{ZnSe}$ signal intensity in the Raman mapping, which facilitates electron transport across the CZTSe/ZnSe interface. 
We performed temperature-dependent I-V measurements to further investigate the carrier transport and recombination at the front and rear interfaces (Figure S5). Figure 2e shows the temperature-dependent $A$ extracted from the dark J-V curves. $A$ is larger than 2 when the temperature is lower than $200 \mathrm{~K}$, suggesting that the device does not behave as an ideal diode in this temperature region..$^{39}$ One possible explanation is that the tunnelling transport process at the $\mathrm{CZTSe} / \mathrm{ZnSe} / \mathrm{CdS}$ heterostructure starts to limit the current when the temperature is lower than $200 \mathrm{~K}$. This limitation is more severe when the temperature is lower because of the lack of sufficient thermal energy that is required for the tunnelling transport. ${ }^{40}$ Since the $A$ is around 1.5 without significant change when the device temperature is within the range of $260-320 \mathrm{~K}$, the device behaves like an ideal diode in this temperature region. Therefore, it is possible to extract the recombination activation energy, $E_{A}$, within this temperature region using the ideal one diode model: ${ }^{41}$

$$
V_{O C}=\frac{E_{A}}{q}-\frac{A k_{B} T}{q} \ln \left(\frac{J_{00}}{J_{L}}\right)
$$

where $q$ is the unit charge, $k_{B}$ is the Boltzmann's constant, $T$ is the temperature, $J_{00}$ is the prefactor of diode current, and $J_{L}$ is the photocurrent. Here, $J_{00}, J_{L}$, and $E_{A}$ are assumed to be weakly temperaturedependent in the temperature region used for fitting. ${ }^{41}$ The temperature-dependent $V_{O C}$ shows good linear behavior in this temperature region (Figure 2f) and the fitted $E_{A}$ is $1.025 \pm 0.005 \mathrm{eV}$, well aligned to the bandgap of the CZTSe absorber $\left(1.03 \mathrm{eV}\right.$, Figure S6). This indicates that the $E_{A}$ deficit compared to $E_{g}$ is no longer a limitation in these CZTSe devices, owing to the passivated heterojunction interface by the epitaxial ZnSe nano-layer and the suppressed bandgap/potential fluctuation as reported previously. ${ }^{22}$

The blocking barrier height of the back contact interface is derived from the temperature dependent series resistance $\left(\mathrm{R}_{\mathrm{S}}\right)$ over the $200 \sim 320 \mathrm{~K}$ temperature range where the device behaves consistently with the thermal emission model. ${ }^{42,43}$ The fitted barrier height is only $11 \pm 5 \mathrm{meV}$ (Figure 2g), much smaller than the previously reported value, ${ }^{44}, 45$ indicating a quasi-ohmic contact at the back contact interface. This 
greatly contributes to the relatively high $\mathrm{FF}$ of over $70 \%$, indicating that the fine grain layer at the bottom of the CZTSe layer is not a significant limitation to the back contact resistance. This is highly likely as the involved $\mathrm{Cu}_{2-\mathrm{x}} \mathrm{Se}$ and $\mathrm{SnSe}_{\mathrm{x}}$ phases at the back contact interface are known to be heavily doped p-type materials, allowing for good conductance. ${ }^{46,47}$
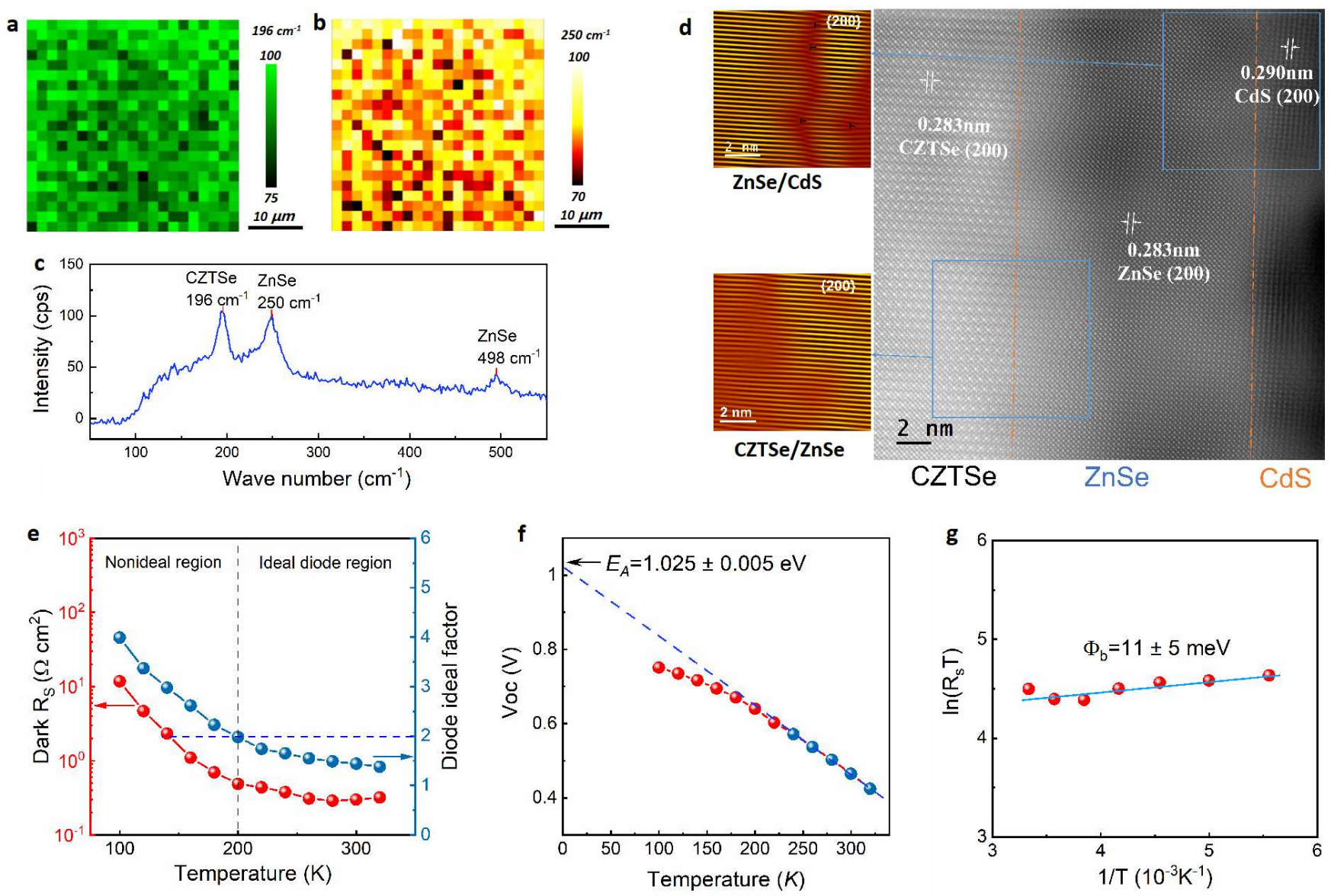

Figure 2. Structure and carrier transport performances of the front and rear interfaces. $a$ and $b$ Color coded Raman mapping at peak positions of $196 \mathrm{~cm}^{-1}$ (A mode of CZTSe) and $250 \mathrm{~cm}^{-1}$ (A1 mode of $\mathrm{ZnSe}$ ), respectively. c Average Raman spectrum of the mapping. The Raman mapping was performed using $441 \mathrm{~nm}$ He-Cd laser as excitation. d HRTEM image and the color-coded inverse fast Fourier transformation (FFT) images of the selected reflections revealing the dislocations (T marked) at the $\mathrm{CZTSe} / \mathrm{ZnSe} / \mathrm{CdS}$ heterointerface. The yellow dashed lines roughly indicate the boundaries of different phases. e Temperature-dependent series resistance (Rs) and diode ideality factor extracted from temperature dependent J-V curves (Figure S5). The black dashed line indicates the boundary between the ideal device region and nonideal device region. $\mathbf{f}$ Plot of $\mathrm{V}_{O C}$ vs. temperature and the linear fit of the recombination activation energy $E_{A}$. The data of blue dots are selected for fitting. $g$ Plot of $\ln \left(R_{S} T\right) v s$. $1 / \mathrm{T}$ and the linear fitting showing back contact barrier height. 


\section{Carrier collection behavior at GBs and GIs}

We performed electron beam induced current (EBIC) measurement to directly investigate the carrier collection in the CZTSe solar cell. Figures 3 a and $\mathbf{b}$ show the SEM and EBIC images of the corresponding cross-section of the CZTSe solar cell at a beam energy of $5 \mathrm{keV}$. The high spatial resolution of the EBIC image enables us to further investigate the electron transport across the GBs. It is noteworthy that the CZTSe grains underneath near-horizontal GBs, not directly connected to the buffer layer (indicated by the yellow and red frames in Figures 3 a and b), do not contribute to the EBIC signal. This indicates significant recombination and/or a carrier transport barrier may exist near these GBs or inside these grains, which may be responsible for the additional $\mathrm{J}_{\mathrm{SC}}$ loss in the long wavelength region. 

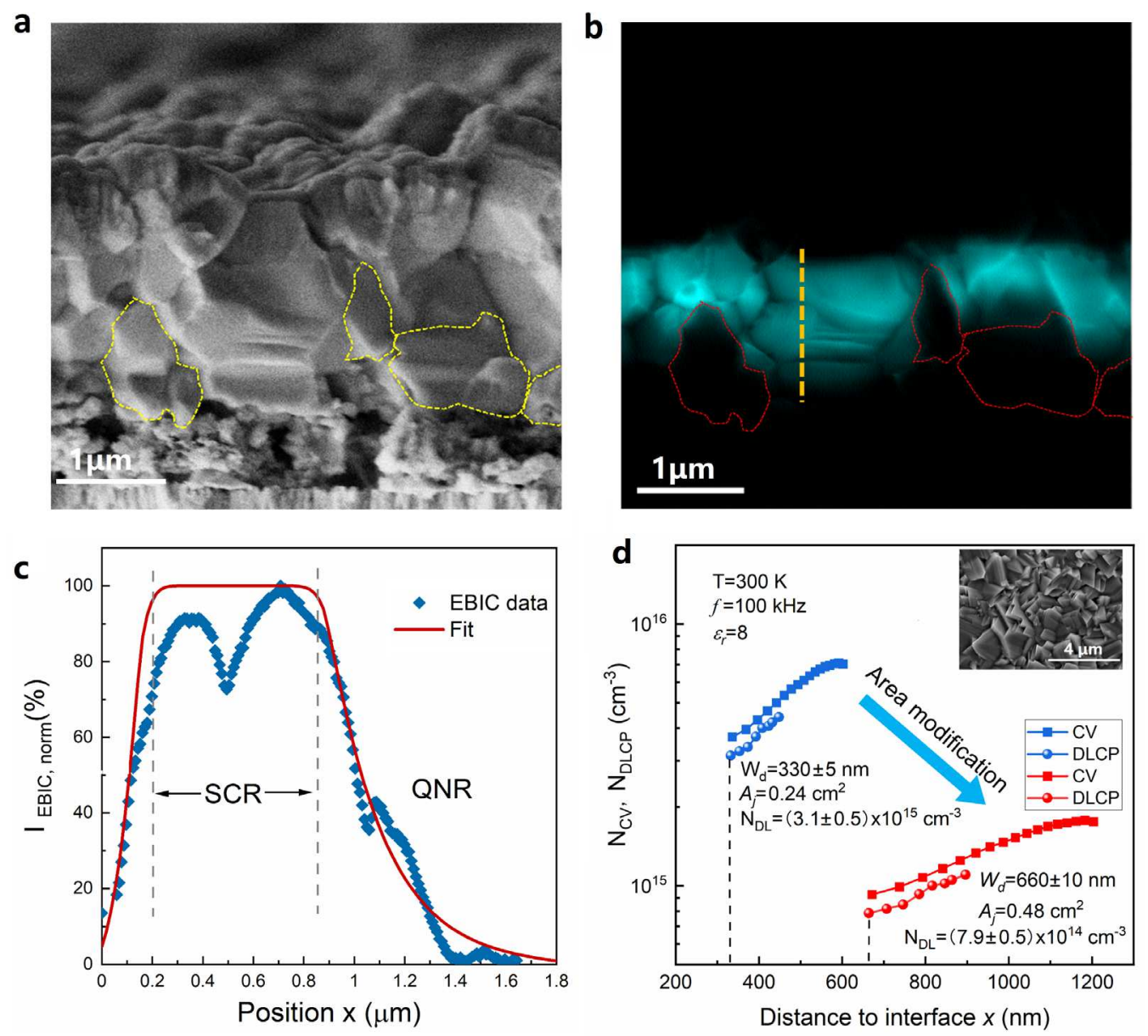

Figure 3. Electron beam-induced current and carrier density analysis. a Cross-section SEM image and $\mathbf{b}$ EBIC image of a cleaved CZTSe device. The yellow frames are eye guides locating the boundaries of the CZTSe grains which do not contribute to the EBIC signal (the regions within the red frames in EBIC image). The beam energy was $5 \mathrm{keV}$. c extracted EBIC profile along the yellow dash line (blue dots) and the fit with analytical model (red line); scan is from top to bottom of the yellow line in $\mathbf{b}$. The space charge region (SCR) and quasi-neutral region (QNR) are highlighted with the vertical dash lines. The fluctuation of EBIC signal is induced by the rough morphology. The regions with protrusions show weak EBIC because of the higher reflection of electron beam, and vice versa. $\mathbf{d}$ Carrier density profiles measured with $\mathrm{C}-\mathrm{V}$ and DLCP with junction area before (blue) and after (red) modification. The depletion region $\mathrm{W}_{\mathrm{d}}$ in of the area-modified data is calibrated with the value fitted from EBIC data. Inset: the surface SEM image of CZTSe absorber.

Figure 3 c shows a representative cross-sectional line-scan extracted from a reasonably flat region without near-horizontal GB, and the fitting of these data using the analytical approach described in Ref. $\left[{ }^{48}\right]$. The 
fitted space charge region (SCR) width is around $660 \mathrm{~nm}$, the electron diffusion length is around $250 \mathrm{~nm}$, and the back surface recombination velocity is around $10^{7} \mathrm{~cm} \mathrm{~s}^{-1}$. As the excitation depth of the acceleration voltage used in EBIC (at $5 \mathrm{kV}$ ) is estimated to be only about $100 \mathrm{~nm}$ (Figure S7), it can be expected that the decay of EBIC in the quasi-neutral region (QNR) may be significantly enhanced by recombination at the unpassivated cross-section surface, thus, underestimating the intragrain electron diffusion length. The intragrain electron diffusion lengths in the QNR can be estimated roughly to be about 0.6-0.7 $\mu \mathrm{m}$ for assumed surface-recombination velocities of $10^{6}-10^{7} \mathrm{~cm} \mathrm{~s}^{-1}$ using the analytical approach described in Ref.[ $\left[{ }^{49}\right]$.

Considering the rough surface of the CZTSe absorber (inset of Figure $\mathbf{3} \mathbf{d}$ ), the effective junction interface area can be significantly larger than the device area. Therefore, we calibrated the space charge region (SCR) width determined by capacitance-voltage $(\mathrm{C}-\mathrm{V})$ measurements and the drive level capacity profile (DLCP) measurements using the value obtained from the EBIC (660 nm), which enables us to better estimate the real net carrier density in the CZTSe absorber and the charged interface defect density. Using the single-side abruption junction mode (ignoring the depletion region in the n-type buffer and window layer), the SCR width ( $\left.W_{S C R}\right)$ and the doping density $\left(N_{D L}\right)$ of the CZTSe absorber can be calculated as following: $:^{50}$

$$
\begin{aligned}
W_{S C R} & =\varepsilon_{0} \varepsilon_{r} A_{j} / C_{0}, \\
N_{D L} & =-C_{0}^{3} / 2 q \varepsilon_{0} \varepsilon_{r} A_{j}^{2} C_{1},
\end{aligned}
$$

where $\varepsilon_{0}$ and $\varepsilon_{r}$ are the vacuum permittivity and relative permittivity of CZTSe respectively, $A_{j}$ is the junction interface area, and $C_{0}$ and $C_{1}$ are the static capacitance and the first order differential capacitance, respectively. When $A_{j}$ is set to the device area, $W_{S C R}$ is $330 \mathrm{~nm}$ and $N_{D L}$ is $3.1 \times 10^{15} \mathrm{~cm}^{-3}$ (Figure 3d). The fitted $W_{S C R}$ from the cross-section EBIC profiles is in the range of 650 to $750 \mathrm{~nm}$ (Figure S8 and S9). 
When $W_{S C R}$ is set to $660 \mathrm{~nm}$, the effective junction interface area is calculated to be twice of the device area, and the real average $N_{D L}$ is about $8.0 \times 10^{14} \mathrm{~cm}^{-3}$. This relatively low net carrier density may significantly limit the quasi-fermi level splitting (QFLS) given the limited minority carrier lifetime, thus leading to large $\mathrm{V}_{\mathrm{OC}}$ loss $\left(\mathrm{V}_{\mathrm{OC}, \text { loss }}\right)$ as will be revealed by the following $3 \mathrm{D}$ device simulation.

We investigated the electrostatic potential fluctuation between grains and the band bending at GBs by means of combining atomic force microscopy (AFM) and Kelvin probe force microscopy (KPFM) on a fresh cleaved cross-section, as shown in Figure 4a and b. The horizontal line-scan of CPD (Figure 4c) indicates a relatively uniform electrostatic potential distribution between the grains even though the topology fluctuation is large, highlighting that the impact of the topology on the CPD is small. The electrostatic potential fluctuation is only $5.4 \mathrm{meV}$. The $\mathrm{V}_{\mathrm{OC}, \text { loss }}$ due to the lateral electrostatic potential fluctuation, $\Delta \varphi$ could be estimated using the following equation: ${ }^{51}$

$$
V_{o c, l o s s}=\Delta \varphi^{2} / 2 q k_{B} T
$$

The $V_{O C, l o s s}$ estimated via Equation (4) is only about $0.6 \mathrm{mV}$, which is negligible. The extracted band bending at the GB1 to GB5 is very small. As shown in Figure 4d, the band bending at GB1 is $8 \mathrm{meV}$ (upward), while the band bending of GB2 to GB5 is negligible (Figure S10). The local chemical composition near GBs was investigated using an EDXS Line-scan. A small Cu peak is observed at the GB region (Figure S11), which has also been observed in other CZTSe and CIGS solar cells, ${ }^{52,53}$ and has been deemed detrimental for device performance. 
a
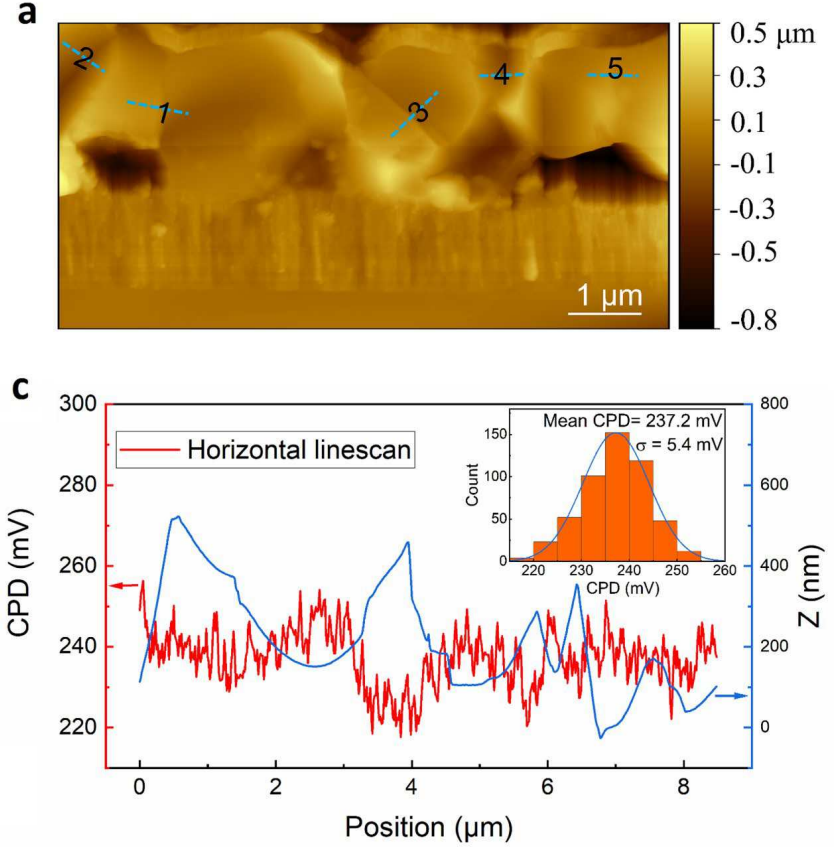

b
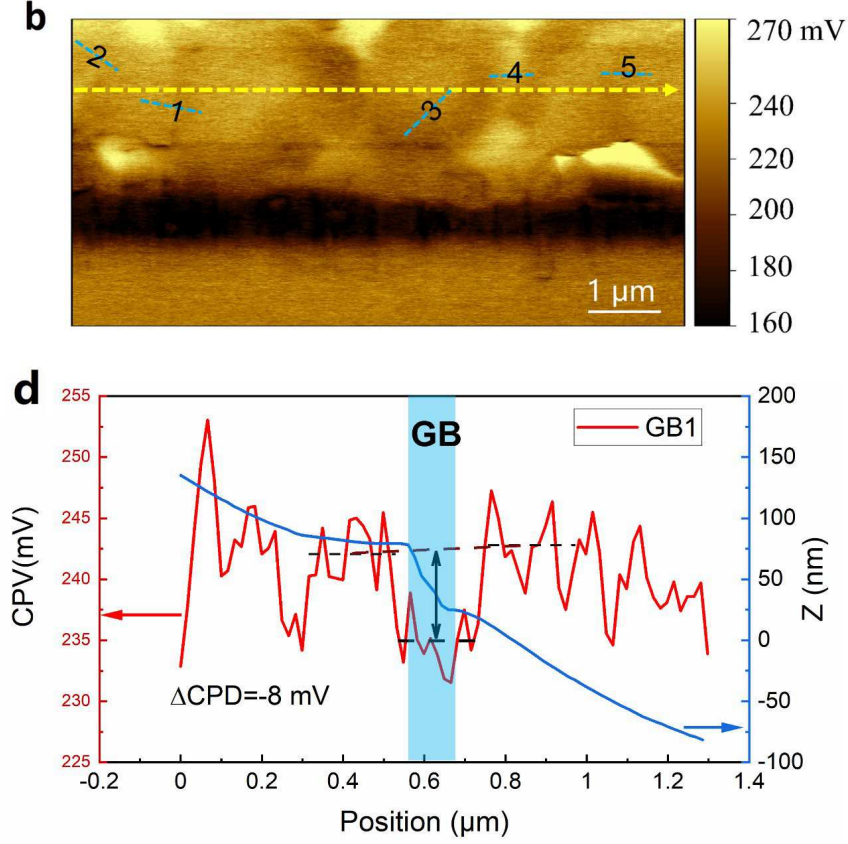

Figure 4. Kelvin Probe Force Microscope and GB composition analysis. Topology image measured with AFM (a) and the corresponding KPFM image (b) of a fresh cleaved CZTSe cell. The blue dash lines labeled with numbers indicate where the GB profiles were extracted. contact potential difference (CPD) and topology profiles extracted along the yellow (horizontal) dash line in $\mathbf{b}$. Inset of $\mathbf{c}$ : the statistic CPD distribution of horizontal scan, showing a mean CPD of $237.2 \mathrm{mV}$ and a standard deviation of $5.4 \mathrm{mV}$. d The CPD and topology profiles of GB1 (indicated in $\mathbf{a}$ and $\mathbf{b}$ ). The bend bending at GB1 is about $-8 \mathrm{meV}$ (upward). The CPD and topology profiles of GB2-GB5 are shown in Figure S10.

\section{Radiative and non-radiative recombination at GBs and GIs}

To quantify the non-radiative recombination velocity at the GBs, $S_{G B}$, we performed cathodoluminescence (CL) mapping of a cross-section CZTSe absorber prepared using an FIB. As shown in Figure 5a, the grains at the top and bottom of the CZTSe layer show comparable CL intensities whilst the CL intensities at the GBs are much lower compared to the GIs. This verifies that the poor carrier collection efficiency in the bottom grains observed in EBIC can be attributed to their relatively larger $S_{G B}$ rather than to the recombination inside the GIs. Figure 5b shows CL line-scans across two representative GBs. No obvious luminescence emission peak variation is observed at the GBs which could indicate that the band gap does 
not change at the GBs. The value of $S_{G B}$ can be estimated using the decay of CL intensities between GBs and GIs (shown in Figure 5c), according to the model described in Ref. $\left[{ }^{54}\right]$ :

$$
\ln [\Delta I(x)]=\ln [S /(S+1)]-x / L,
$$

where $\Delta I(x)$ is the relative CL intensity between the GBs and GIs, $L$ is the electron diffusion length, $S$ the reduced recombination velocity $\left(S=S_{G B} \tau_{G I} L\right)$, and $x$ is the position of the electron beam. The linear fittings of $S$ are shown in Figure 5d. Assuming the photoluminescence (PL) decay time $\tau_{\text {eff }}$ is dominated by the GB recombination, i.e. $\tau_{e f f}$ is in the range of 3.3-8.6 $\mathrm{ns}$ as measured by time-resolved photoluminescence (TRPL; Figure 5e). Here, we adopt an intragrain lifetime, $\tau_{G I}$ of $10 \mathrm{~ns}$, the lower limit based on the 3D device simulation as will be shown below. The estimated $S_{G B}$ is in a range of (1.3-1.7) $\times 10^{4} \mathrm{~cm} \mathrm{~s}^{-1}, 1-2$ orders of magnitude larger than the value reported for high efficiency CIGSSe and CdTe solar cells. ${ }^{35,36}$ As the band bending at GBs is negligible, the effective GB recombination velocity is not affected by band bending and should be close to the $S_{G B}{ }^{55}$ It is noteworthy that the high recombination velocity at the GBs may also exist in sulfur-mixed CZTSSe and CZTS materials, indicating that more pertinent research efforts such as grain boundary chemistry and passivation strategies are urgently needed for kesterite solar cells. 
a

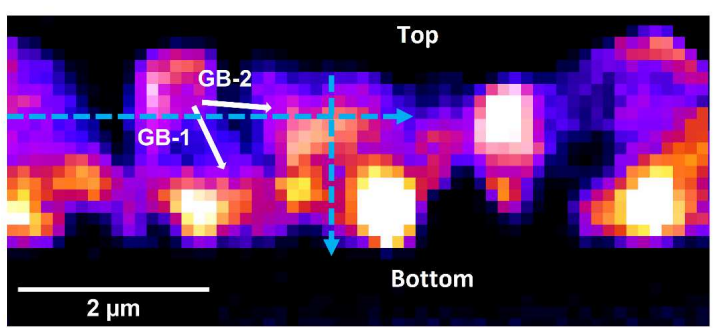

b

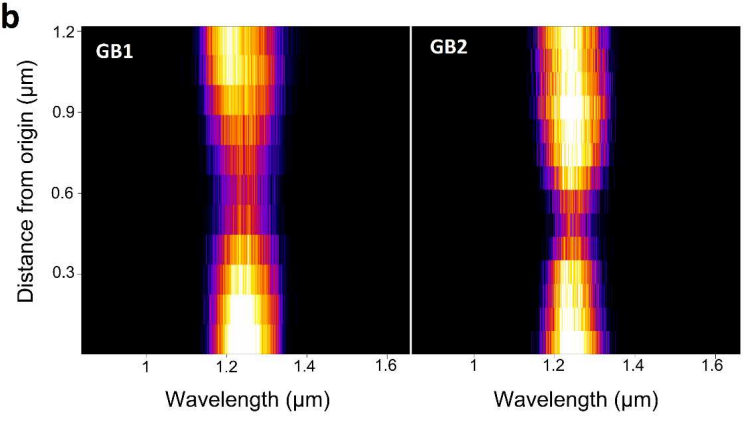

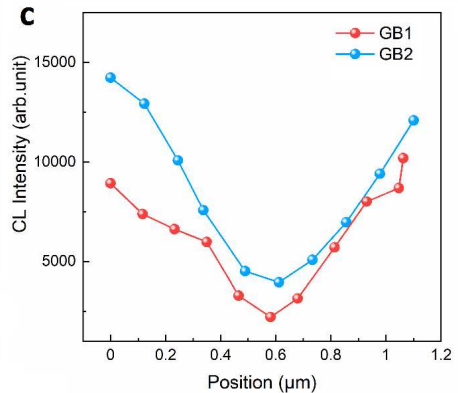

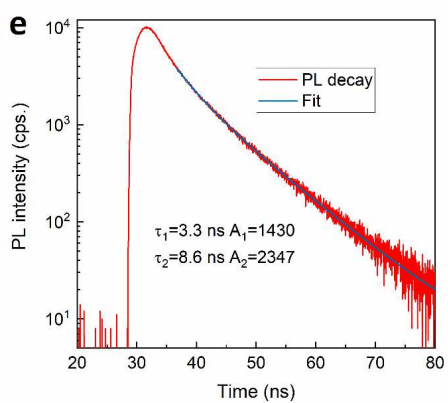

d

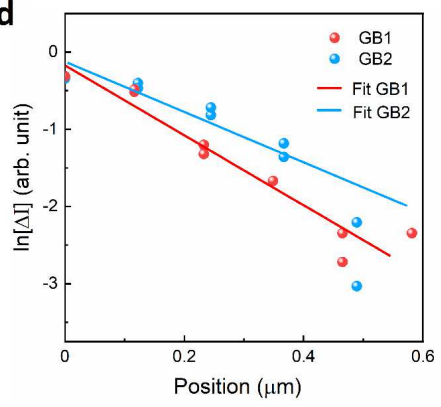

g

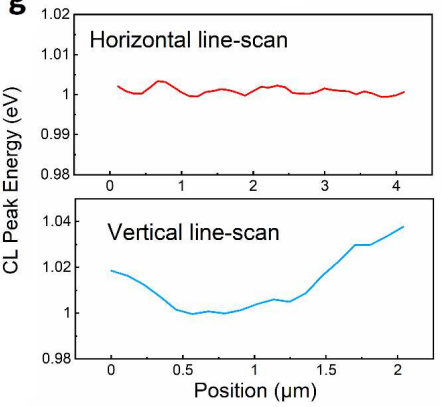

Figure 5. Cathodoluminescence and photoluminescence analysis. a Hyperspectral and intensity combined CL map acquired at $10 \mathrm{keV}$ from an FIB prepared cross-section sample of CZTSe absorber. The SEM image is shown in Figure S12. b Spectro-, spatial-, and intensity- resolved CL maps of the two GBs indicated in a. c Extracted CL intensity profiles across the two GBs. $\mathbf{d} \ln [\Delta \mathrm{I}]$ plots of the CL intensity profiles for positive distance values. The red and blue solid lines are the linear regressions. e Timeresolved photoluminescence (TRPL) measured with $532 \mathrm{~nm}$ laser and its corresponding double exponential decay fit. $\mathrm{g}$ the extracted CL peak energy profiles alone the horizontal and vertical blue dash arrows indicated in $\mathbf{a}$.

In addition, we further investigated the bandgap fluctuation in the CZTSe absorber by horizontal and vertical line-scans of CL peak energies. The positions of these line-scans are indicated in Figure 5a and the results are shown in Figure 5g. The horizontal CL emission peak fluctuation at the region near the junction interface is rather small $(<5 \mathrm{meV})$, suggesting that the radiative recombination owing to lateral bandgap fluctuation is negligible. In contrast, the front and rear surface regions show slightly increased CL emission peak compared to the bulk by $20-40 \mathrm{meV}$, which could be attributed to an increased band gap correlating with the relatively high sodium concentration at the top and bottom (Figure S13). The incorporation of $\mathrm{Na}$ is known to slightly increase the bandgap of kesterite. ${ }^{56}$ The minimum CL peak energy 
at the bulk is around $1.00 \mathrm{eV}$, slightly lower than the PL peak energy (1.02 eV, Figure S14) and the optical bandgap $(1.03 \mathrm{eV})$, which may contribute to $\sim 30 \mathrm{mV} \mathrm{V}_{\mathrm{OC} \text {,loss }}$ due to sub-bandgap radiative recombination.

\section{$3 D$ device simulations}

To further investigate how the GB and GI recombination impacts the device performance, we employed 3D device simulations to fit the $12.45 \%$ efficiency CZTSe device and estimate pathways for further improvement. The simulations were based on a 3D unit cell established using the experimental photoelectronic parameters and the equivalently topology extracted from the morphology in the SEM and TEM images (see the details in Methods: 3D device simulation, Table S1, and Figure S15-S17). The 12.45\% efficient CZTSe cell was reasonably reproduced using this unit cell by matching the J-V and EQE curves (Figure S18). The fitted $S_{G B}$ is $0.7 \times 10^{4} \mathrm{~cm} \mathrm{~s}^{-1}$, which is slightly smaller than the value measured from CL mapping. Assuming that the grains of CZTSe absorber are approximately cubic-like, $S_{G B}$ is uniformly distributed at GBs including the top and bottom surfaces, the minority carrier lifetime determined by GB recombination, $\tau_{G B}$, in a cubic-like grain with a grain size $d$ can be estimated using the following equation: $:^{57}$

$$
\tau_{G B} \cong \frac{V}{S_{G B} \cdot S_{a}}+\frac{\alpha d^{2}}{D_{e}}=\frac{d}{6 S_{G B}}+\frac{\alpha q d^{2}}{\mu_{e} k_{B} T}
$$

where $V$ is the volume of the grain, $S_{a}$ is the surface area, $\alpha$ is the constant determined by the cubic-like boundary conditions, $D_{e}$ is the diffusivity of minority carriers, and $\mu_{e}$ is the minority carrier mobility. The first term at the right side of Equation (6) is determined by the recombination rate at GBs, while the second term is determined by the arrival rate of minority carriers diffusing from GI to GBs. Considering that the value of $\alpha$ should be much smaller than that for Si wafers $\left(\alpha=1 / \pi^{2}\right)^{57}$ as there are four more recombination active surfaces for cubic-like grains, and that the electron mobility of CZTSe is relatively 
large compared to the grain size $d,{ }^{37,58}$ we believe the second term determined by the arrival rate can be negligible. Therefore, using the simulated value of $S_{G B}$, the calculated value of $\tau_{G B}$ of our CZTSe absorber with a grain size of $1.1 \mu \mathrm{m}$ is $2.6 \mathrm{~ns}$. Assuming the top surface is well passivated by the $\mathrm{ZnSe}$ nano layer, the constant 6 in Equation (6) should be changed to 5 and the amended $\tau_{G B}$ is $3.1 \mathrm{~ns}$, very close to the fast decay time measured from TRPL ( $3.2 \mathrm{~ns})$ which is believed to be a key parameter determining $\mathrm{V}_{\text {OC. }}{ }^{59}$ The effective minority carrier lifetime $\tau_{\text {eff }}$ could be expressed as: ${ }^{60}$

$$
\frac{1}{\tau_{e f f}}=\frac{1}{\tau_{G B}}+\frac{1}{\tau_{G I}}+\frac{1}{\tau_{\text {int }}}+\frac{1}{\tau_{\text {rad }}}
$$

where $\tau_{G I}$ is the intragrain minority carrier lifetime, $\tau_{i n t}$ the interface recombination lifetime, $\tau_{\text {rad }}$ the radiative recombination lifetime. Due to the low carrier density in the CZTSe absorber, the radiative recombination is negligible under low injection condition (one sun). According to the simulated impact of $\tau_{G I}$ (Table S2), the photovoltaic parameters fit best when $\tau_{G I}$ is 50-100 ns. On the other hand, considering that slight deviations could be involved in the device simulation, it is possible that the lower limit of $\tau_{G I}$ can be $10 \mathrm{~ns}$. Assuming that the junction interfacial recombination is also negligible, and the rear interfacial recombination can be included in the GB recombination, the value of $\tau_{\text {eff }}$ is dominated by $\tau_{G B}$. Equitation (6) predicts that $\tau_{G B}$ approximately linearly increase with grain size $d$. Therefore, grain size could be a critical factor that determines $\tau_{\text {eff }}$ assuming that the $S_{G B}$ stays the same.

The impact of grain boundary recombination velocity is simulated and shown in Table 1. It shows that reducing the value of $S_{G B}$ to $10^{2}-10^{3} \mathrm{~cm} \mathrm{~s}^{-1}$ (comparable with high efficiency CIGS and CdTe solar cells) gives rise to only an additional $30 \mathrm{mV}$ to $\mathrm{VOC}_{\mathrm{OC}}, 5 \%$ absolute increase of $\mathrm{FF}$, a marginal increase of $\mathrm{J}_{\mathrm{SC}}$, and a $\sim 2 \%$ absolute increase of PCE. The improved $V_{\text {OC }}$ is in good accordance with the value of the etched single-crystalline CZTSe solar cells. ${ }^{61}$ The device performance in this region is mainly limited by the 
relatively low carrier density and the limited $\tau_{G I}$. However, if $S_{G B}$ increases to above $10^{4} \mathrm{~cm} \mathrm{~s}^{-1}$, all the photovoltaic performance parameters significantly decrease, indicating large $S_{G B}$ is the limiting factor in this region. The simulations indicate only a marginal benefit by further improving $\tau_{G I}$ (Table S2). This is because the effective minority carrier lifetime $\tau_{\text {eff }}$ is limited by the low $\tau_{G B}$ as discussed above. However, if the grain quality is degraded, the cell performance is severely impacted. Table 2 shows the impact of the carrier density on the device performance. The results indicate that significant $\mathrm{V}_{\mathrm{OC}}$ and FF increases could be achieved if the carrier density is improved to $5 \times 10^{16} \mathrm{~cm}^{-3}$, a typical carrier density level for $>20 \%$ efficient CIGS and CdTe solar cells, ${ }^{35,62}$ resulting in efficiency beyond 15\%. The impact of grain size on device performance was also simulated. Larger grain size will lead to better performance (Table S3) because both $\tau_{G B}$ and $\tau_{\text {eff }}$ linearly increases with grain size as described by Equation (6) and Equation (7).

Table 1. Simulated impact of GB recombination on device performance, with intragrain lifetime $50 \mathrm{~ns}$ and net carrier density $8 \times 10^{14} \mathrm{~cm}^{-3}$.

\begin{tabular}{|c|c|c|c|c|c|c|c|}
\hline$S_{G B}\left(\mathrm{~cm} \mathrm{~s}^{-1}\right)$ & $10^{0}$ & $10^{2}$ & $10^{3}$ & $10^{4}$ & $10^{5}$ & $10^{6}$ & $10^{7}$ \\
\hline $\mathrm{V}_{\mathrm{oc}}(\mathrm{mV})$ & 508 & 507 & 500 & 473 & 438 & 411 & 406 \\
\hline$\eta(\%)$ & 14.4 & 14.3 & 13.9 & 11.9 & 8.9 & 7.0 & 6.6 \\
\hline $\mathrm{J}_{\mathrm{sc}}\left(\mathrm{mA} \mathrm{cm} \mathrm{cm}^{-2}\right)$ & 37.5 & 37.4 & 37.4 & 36.7 & 33.9 & 31.2 & 30.6 \\
\hline FF (\%) & 75.6 & 75.5 & 74.5 & 68.8 & 60.0 & 54.7 & 52.8 \\
\hline
\end{tabular}

Table 2. Simulated impact of carrier density on device performance, with intragrain lifetime $50 \mathrm{~ns}$ and $S_{G B} 7000 \mathrm{~cm} \mathrm{~s}^{-1}$.

\begin{tabular}{|c|c|c|c|c|c|c|}
\hline $\begin{array}{l}\text { Carrier density } \\
\left(\mathrm{cm}^{-3}\right)\end{array}$ & $10^{14}$ & $5 \times 10^{14}$ & $10^{15}$ & $5 \times 10^{15}$ & $10^{16}$ & $5 \times 10^{16}$ \\
\hline $\mathrm{V}_{\mathrm{oc}}(\mathrm{mV})$ & 34.9 & 36.7 & 37.0 & 36.9 & 36.5 & 35.1 \\
\hline$\eta(\%)$ & 438 & 482 & 486 & 499 & 507 & 549 \\
\hline $\mathrm{J}_{\mathrm{sc}}\left(\mathrm{mA} \mathrm{cm}{ }^{-2}\right)$ & 8.9 & 11.9 & 12.6 & 13.8 & 14.2 & 15.2 \\
\hline $\mathrm{FF}(\%)$ & 58.2 & 67.1 & 70.0 & 75.1 & 77.0 & 79.1 \\
\hline
\end{tabular}


The above results indicate the device performance of the investigated $12.45 \%$ efficient CZTSe solar cells is limited by the recombination at GBs and the low net carrier density. Although grain interior lifetime is important when its value is lower than $10 \mathrm{~ns}$, further improving grain interior lifetime to longer than 50 ns would not give any improvement in device performance if the grain boundary recombination cannot be reduced. This may explain why various extrinsic doping/alloying strategies that are anticipated to improve bulk qualities can improve device performance when the baseline efficiency is low, but hardly further improve the efficiency if the baseline efficiency is at a level of $12-13 \%$ and GBs are not passivated. On the other hand, as long as the density of acceptor-like interface defects can be kept low, higher net carrier density will not lead to significant interfacial recombination. ${ }^{63}$ Considering the radiatively limited lifetime versus carrier density of CZTSe materials (Figure S19), an increase in carrier density to about $5.0 \times 10^{16}$ $\mathrm{cm}^{-3}$ would be beneficial for the open-circuit voltage when the intragrain lifetime is $50-100 \mathrm{~ns}$, which is an essential direction to improve the efficiency to $15 \%$ and beyond.

\section{Conclusion}

In summary, we have successfully unveiled most of the important microscopic loss mechanisms in our $\geq 12 \%$ efficiency CZTSe solar cells. The results indicate that the junction interface is well passivated by an epitaxial ZnSe nano layer, the radiative recombination loss through sub-band recombination and electrostatic potential fluctuation is small, and that the intragrain minority carrier lifetime is larger than $10 \mathrm{~ns}$, all of which are encouraging characteristics for high efficiency solar cells. Instead, the high effective recombination velocity at grain boundaries $\left(\geq 10^{4} \mathrm{~cm} \mathrm{~s}^{-1}\right)$ and the low net carrier density $\left(\sim 10^{15}\right.$ $\mathrm{cm}^{-3}$ ) are the current main limiting factors of our CZTSe solar cells. This provides clear directions for improving the performance of Se-based kesterite solar cells. We believe the established framework to reveal the important microscopic loss mechanisms of thin-film solar cells could also be applicable to other emerging materials like perovskite and antimony chalcogenides. 


\section{Methods}

\section{Film and Device fabrication:}

CZTSe films were fabricated with sputtering stacked $\mathrm{Cu}-\mathrm{Zn}-\mathrm{Sn}$ metallic precursors on Mo-coated glass substrates, followed by a selenization growth process. The target composition of the CZTSe absorber is $\mathrm{Cu} /(\mathrm{Zn}+\mathrm{Sn}) \approx 0.75$ and $\mathrm{Zn} / \mathrm{Sn} \approx 1.1$, measured with $\mathrm{X}$-ray Fluorescence spectrometer $(\mathrm{XRF}) . \mathrm{The} \mathrm{Cu}, \mathrm{Zn}$, and Sn targets are with $99.999 \%$ purity. The precursor stacking order was $\mathrm{Mo} / \mathrm{Sn} / \mathrm{Cu} / \mathrm{Zn} / \mathrm{Sn} / \mathrm{Cu}$, and the sputtering pressure was about $0.2 \mathrm{~Pa}$. The metallic precursors were pre-alloyed at $250{ }^{\circ} \mathrm{C}$ for $15 \mathrm{~min}$, followed by a soft-selenization at $250-280^{\circ} \mathrm{C}$ for $15 \mathrm{~min}$ in controlled low Se partial pressure. Then the substrates were ramp to $550^{\circ} \mathrm{C}$ in $15 \mathrm{~min}$ and dwell at $550^{\circ} \mathrm{C}$ for $8-10 \mathrm{~min}$. The details of the annealing profile are described in Ref.[22]. All these annealing processes were performed in a custom-made furnace which can have independent temperature control of Se source, substrates, and Se cracking barrel (see the schematic diagram in Figure S20). The controlling Se atmosphere by adjusting the Se source temperature and Se cracking barrel temperature was detailed in our early publication. ${ }^{64}$ Some key points for the selenization processes are summarized as follows: i) Before selenization start, a pre-alloying treatment with temperature higher than $250^{\circ} \mathrm{C}$ is important to fabricate compact films, and also important to control the $\mathrm{Sn}$ loss and the thickness of $\mathrm{MoSe}_{2}$ layer; ${ }^{44}$ ii) a sufficient soft selenization with temperature below $300^{\circ} \mathrm{C}$ (to prevent $\mathrm{Sn}$ loss) is important to control the bulk defects by turning $\mathrm{Sn}$ to $\mathrm{Sn}^{4+}$ and facilitating $\mathrm{Zn}$ diffusing to the top region before the synthesis of CZTSe phase start at $350-400^{\circ} \mathrm{C} .^{22} \mathrm{In}$ this soft selenization, it is very important to use a reactive micro-molecule Se vapor $\left(\mathrm{Se}_{2}\right)$ under low Se partial pressure. High Se partial pressure will lead to poor Se diffusion. ${ }^{64}$ iii) Sufficient Se partial pressure during high temperature annealing is important for grain growth. 
The CZTSe devices were fabricated with an architecture of $\mathrm{Mo} / \mathrm{CZTSe} / \mathrm{CdS} / \mathrm{i}-\mathrm{ZnO} / \mathrm{ZnO}: \mathrm{Al} / \mathrm{Ni} / \mathrm{Al} / \mathrm{MgF}_{2}$. A $20-50 \mathrm{~nm}$ CdS buffer layer was deposited at $85^{\circ} \mathrm{C}$ using the chemical bath deposition (CBD) method. A $50 \mathrm{~nm}$ i-ZnO layer and a 400-450 nm ZnO:Al layer were subsequently deposited using radio frequency (RF) and direct current (DC) sputtering, respectively. The $\mathrm{Ni} / \mathrm{Al}$ grids and $110 \mathrm{~nm} \mathrm{MgF}_{2}$ anti-reflector coating were deposited using electron beam evaporation. The total area of each device is about $0.24 \mathrm{~cm}^{2}$ defined by mechanical scribing. Total area efficiencies are reported.

\section{Characterization:}

The compositions of the films were analyzed using an X-ray Fluorescence spectrometer (XRF; ARL Performance'X 4200, Thermo Fisher Scientific) with Uniquant analysis software. Morphological analysis was performed using a Scanning Electron Microscope (SEM; FEI Apreo LoVac). The TEM-ready samples were prepared using the in-situ FIB lift out technique on an FEI Dual Beam FIB/SEM. The samples were capped with sputtered $\mathrm{C}$ and e-Pt/I-Pt prior to milling. The TEM lamella thickness was $\sim 100 \mathrm{~nm}$. The samples were imaged on a Hitachi HD2700 STEM with high-resolution (HR) TEM mode.

EDS spectra were acquired on Oxford INCA, Bruker Quantax EDS system. The current-voltage (J-V) data were acquired using a Keithley 2400 source meter and a Newport solar simulator (ORIEL-SOI3A) under the standard condition $\left(1000 \mathrm{~W} / \mathrm{m}^{2}, 25^{\circ} \mathrm{C}\right.$, AM 1.5 G). A certificated mono-crystalline Si reference solar cell was used to calibrate the light intensity of the solar simulator. The temperature dependent J-V data were measured using a vacuumed cryostat with quartz windows. The light intensity was adjusted according to the $\mathrm{J}_{\mathrm{SC}}$ measured at standard condition (AM 1.5 G, without cryostat). EQE data were acquired by measuring the short-circuit current with spectrally resolved monochromatic beam and locked-in amplifier, using calibrated $\mathrm{Si}$ and $\mathrm{InGaAs}$ photodiodes as references. 
The element depth profiles were recorded by secondary ion mass spectroscopy (SIMS; IMS-6F, CAMECA). Raman spectroscopy was performed using a Renishaw inVia Raman microscope fitted with a $441 \mathrm{~nm} \mathrm{He}-\mathrm{Cd}$ laser as the excitation source, $18001 \mathrm{~mm}^{-1}$ grating, and measured using a 1000× objective. The focal point was above the surface of the sample to collect more signals from the surface of the sample. The pixel size was $2 \mu \mathrm{m} \times 2 \mu \mathrm{m}$.

The EBIC measurements were performed on the cross-section of the finished device using an SEM (Zeiss IIGMA) extended with a tunable current amplifier. The devices were connected to a circuit that provided tunable bias. The EBIC images were obtained with a splitting mode, which was combined with SEM images of the same scanned region. The electron beam energy was $5 \mathrm{keV}$.

The cross-section KPFM measurements were conducted on a fresh cleaved CZTSe cell using atomic force microscopy (Bruker Dimension ICON SPM) with a scan rate of $0.200 \mathrm{~Hz}$ in a scan size of $8.5 \mu \mathrm{m}(\mathrm{W}) \times$ $4.25 \mu \mathrm{m}(\mathrm{H})$. A brand new PtSi probe (Bruker SCM-PTSI) was used in these measurements and the samples were measured using a two-pass scan (one for topography in contact mode and another for contact potential difference $[\mathrm{CPD}]$ maps in non-contact mode). The system deviation of CPD is about $\pm 10 \mathrm{mV}$.

PL and TRPL were measured using a microscope customized for micro-PL measurements. The excitation source was a $532 \mathrm{~nm}$ pump from an EKSPLA PT210 laser at $1 \mathrm{MHz}$ repetition rate and 10 ps pulse width. The TRPL signal was detected using a fiber-coupled InGaAs avalanche photodiode (ID210) and processed using the time-correlated single photon counting board (TimeHarp 260). The time binning is $25 \mathrm{ps}$.

A cross-section sample was prepared for CL by a plasma FIB (Thermo Fisher Helios G4 PFIB) with an in-situ lift-out platform. The electron excitation profile was simulated by the Monte Carlo method using the CASINO software ${ }^{65}$ (Figure S7) to determine the suitable thickness of the sample and acceleration voltage used in the CL measurement. Based on the simulation and considering that the average grain size 
is around $1 \mu \mathrm{m}, 10 \mathrm{kV}$ and $1 \mu \mathrm{m}$ were used for the voltage and targeting thickness of the FIB milled sample, respectively. The sample was transferred and mounted on an in-situ TEM grid with Pt welding after rough milling to about $2 \mu \mathrm{m}$ thick. The sample was further polished using low beam current $(0.3 \mathrm{nA})$ after liftout to achieve $\sim 1 \mu \mathrm{m}$ thickness. Prior to CL measurement, the sample received a final ion beam polish on both faces (Fischione NanoMill 1040) at low voltage (500V) to ensure a clean and fresh surface for analysis. Analysis was conducted using a Delmic SPARC spectral cathodoluminescence system coupled to an FEI Nova Nano SEM 450 field-emission SEM.

\section{$3 D$ device simulation:}

A commercial software package, Sentaurus technology computer-aided design (TCAD) was used to numerically examine the device physics. In this study, a 3D unit cell shown in Figure $\mathbf{S}$ 16a was established in the simulator. In this unit cell, the absorber consists of five grains, one is larger $(1.1 \mu \mathrm{m})$ and the other four are smaller with the same size $(0.5 \mu \mathrm{m})$. The sizes of these grains were averaged from the TEM and SEM results (Figure S13 and S14). After all constitutional regions were generated in the simulator, the whole structure went through a meshing process to break down into millions of small elements i.e. cuboids. A smaller element allows for a higher accuracy to compute the spatial distribution of key fields like carrier concentration. Meanwhile, it demands more computer resources as well. Hence the element size was refined only where the field variation is significant to balance between speed and accuracy. Afterwards, photogeneration was computed with the simple optical beam absorption method using the Beer-Lambert law. The complex refractive index of each layer was obtained from inhouse characterization. The key semiconductor material parameters for electron simulation are listed in Table

S1 and obtained from either inhouse characterization or the literature. ${ }^{66-68}$ The ambient temperature in simulation is also $298.15 \mathrm{~K}$ to match the standard test condition. The tuned lifetime and mobility values are well within the reported range in the literature. 
After initialising all important fields and model parameters, the thermal equilibrium condition was first computed by solving five semiconductor equations i.e. the Poisson, drift-diffusion and carrier continuity equations numerically. A well-established mesh and suitable solver help reach self-consistency fast. Subsequently, the impact of carrier generation and bias voltage was investigated by ramping these parameters dynamically. For each ramping step, the steady state was computed so that key fields can be extracted for further analysis. If necessary, a snapshot at a ramping step can also be saved to preserve spatial distribution of fields. Following this practice, the champion cell was reproduced by matching key performance characteristics. Afterwards, the impact of grain lifetime, doping, size and boundary recombination on cell performance was predicted, providing a guideline for future cell improvement.

\section{Author contributions}

J.L. and X.H conceived the idea, X.H. and M. A. G supervised the project. J. L. fabricated the CZTSe films and solar cells, conducted most of the characterizations and data analysis, and wrote the manuscript. J.H. analyzed the HR-TEM and EBIC data. F.M. did the 3D device simulation. J.L. and H.L. conducted the EBIC measurements. Y.Y., J.L., H.S. conducted KPFM measurements. J.H. and J.C. fabricated the FIB sample for CL mapping. K.P., R.T., J.H., J.L. conducted the CL mapping. R.L.C., Z.H., J.L. conducted the PL and TRPL measurements. M.H. and K.S. assisted in precursor and Window layer fabrication. All authors discussed and commented on the manuscript.

\section{Supporting Information.}

Supporting Information is available at https://doi/xxxxxxxx.

\section{Notes}


The authors declare no competing financial interest.

\section{Acknowledgements}

J. Li, J. Huang, X. Hao, and M.A. Green acknowledge the financial support by the Australian Government through the Australian Renewable Energy Agency (ARENA) (grant no. 2017/RND006), Baosteel (grant no. LP150100911). X. Hao acknowledges the financial support by Australian Research

Council (ARC) Future Fellowship (FT190100756). J. Li. acknowledges the support from Australian Centre of Advanced Photovoltaics (ACAP, RG200768-A). T. U. acknowledges support by the European Union's Horizon 2020 research and innovation programme under grant agreements No. 777968 (INFINITE-CELL project) and 952982 (Custom-Art project). Responsibility for the views, information or advice expressed herein is not accepted by the Australian Government. We thank Porf. Chunsheng Jiang from NREL, USA for the discussion of KPFM measurements. The authors acknowledge the facilities and the scientific and technical assistance of Microscopy Australia at the Electron Microscope Unit (EMU) within the Mark Wainwright Analytical Centre (MWAC) at UNSW Sydney.

\section{References}

1. Creutzig, F.; Agoston, P.; Goldschmidt, J. C.; Luderer, G.; Nemet, G.; Pietzcker, R. C., The underestimated potential of solar energy to mitigate climate change. Nature Energy 2017, 2 (9).

2. Green, M. A., Third generation photovoltaics. 2006.

3. LydiaHWong, A. Z., Jonathan DMajor, Xiaojing Hao , Aron Walsh ,; Saucedo, T. K. T. a. E., Emerging inorganic solar cell efficiency tables (Version 1). J. Phys.: Energy 2019, 2019 (1), 032001.

4. Liu, F.; Zeng, Q.; Li, J.; Hao, X.; Ho-Baillie, A.; Tang, J.; Green, M. A., Emerging inorganic compound thin film photovoltaic materials: Progress, challenges and strategies. Materials Today 2020, $41,120-142$.

5. Zakutayev, A.; Major, J. D.; Hao, X.; Walsh, A.; Tang, J.; Todorov, T. K.; Wong, L. H.; Saucedo, E., Emerging inorganic solar cell efficiency tables (version 2). Journal of Physics: Energy 2021, $3(3)$. 
6. Osbel Almora, D. B., Guillermo C. Bazan, et al., Device Performance of Emerging Photovoltaic Materials (Version 2) Authorea 2021.

7. Giraldo, S.; Jehl, Z.; Placidi, M.; Izquierdo-Roca, V.; Perez-Rodriguez, A.; Saucedo, E., Progress and Perspectives of Thin Film Kesterite Photovoltaic Technology: A Critical Review. Adv Mater 2019, 31 (16), e1806692.

8. Walsh, A.; Chen, S.; Wei, S.-H.; Gong, X.-G., Kesterite Thin-Film Solar Cells: Advances in Materials Modelling of Cu2ZnSnS4. Advanced Energy Materials 2012, 2 (4), 400-409.

9. Son, D.-H.; Kim, S.-H.; Kim, S.-Y.; Kim, Y.-I.; Sim, J.-H.; Park, S.-N.; Jeon, D.-H.; Hwang, D.-K.; Sung, S.-J.; Kang, J.-K., Effect of solid-H $2 \mathrm{~S}$ gas reactions on CZTSSe thin film growth and photovoltaic properties of a 12.62\% efficiency device. Journal of Materials Chemistry A 2019.

10. Wang, W.; Winkler, M. T.; Gunawan, O.; Gokmen, T.; Todorov, T. K.; Zhu, Y.; Mitzi, D. B., Device Characteristics of CZTSSe Thin-Film Solar Cells with 12.6\% Efficiency. Advanced Energy Materials 2014, 4 (7), 1301465.

11. Best Research-Cell Efficiency chart, regularly updated by NREL, http://www.nrel.gov/ncpv/images/efficiency_chart.jpg, (accessed: December 2021).

12. Matare, H. J. J. o. A. P., Carrier transport at grain boundaries in semiconductors. 1984, 56 (10), 2605-2631.

13. Siebentritt, S.; Igalson, M.; Persson, C.; Lany, S., The electronic structure of chalcopyrites-bands, point defects and grain boundaries. Progress in Photovoltaics: Research and Applications 2010, 18 (6), $390-410$.

14. Kurtz, S. R.; McConnell, R. In Requirements for a 20\%-efficient polycrystalline GaAs solar cell, AIP Conference Proceedings, American Institute of Physics: 1997; pp 191-205.

15. Green, M. A.; Dunlop, E. D.; Hohl - Ebinger, J.; Yoshita, M.; Kopidakis, N.; Hao, X., Solar cell efficiency tables (Version 58). Progress in Photovoltaics: Research and Applications 2021, 29 (7), 657-667.

16. Yun, J. S.; Ho-Baillie, A.; Huang, S.; Woo, S. H.; Heo, Y.; Seidel, J.; Huang, F.; Cheng, Y. B.; Green, M. A., Benefit of Grain Boundaries in Organic-Inorganic Halide Planar Perovskite Solar Cells. $J$ Phys Chem Lett 2015, 6 (5), 875-80.

17. Li, C.; Wu, Y.; Poplawsky, J.; Pennycook, T. J.; Paudel, N.; Yin, W.; Haigh, S. J.; Oxley, M. P.; Lupini, A. R.; Al-Jassim, M.; Pennycook, S. J.; Yan, Y., Grain-boundary-enhanced carrier collection in CdTe solar cells. Physical review letters 2014, 112 (15), 156103.

18. Gloeckler, M; Sites, J. R.; Metzger, W. K., Grain-boundary recombination in Cu(In,Ga)Se2 solar cells. Journal of Applied Physics 2005, 98 (11).

19. Lin, T.-Y.; Khatri, I.; Matsuura, J.; Shudo, K.; Huang, W.-C.; Sugiyama, M.; Lai, C.-H.; Nakada, T., Alkali-induced grain boundary reconstruction on $\mathrm{Cu}(\mathrm{In}, \mathrm{Ga}) \mathrm{Se} 2$ thin film solar cells using cesium fluoride post deposition treatment. Nano Energy 2020, 68.

20. Muzzillo, C. P.; Poplawsky, J. D.; Tong, H. M.; Guo, W.; Anderson, T., Revealing the beneficial role of $\mathrm{K}$ in grain interiors, grain boundaries, and at the buffer interface for highly efficient CuInSe 2 solar cells. Progress in Photovoltaics: Research and Applications 2018, 26 (10), 825-834.

21. Chen, S.; Walsh, A.; Gong, X. G.; Wei, S. H., Classification of lattice defects in the kesterite $\mathrm{Cu} 2 \mathrm{ZnSnS} 4$ and $\mathrm{Cu} 2 \mathrm{ZnSnSe} 4$ earth-abundant solar cell absorbers. Adv Mater 2013, 25 (11), 1522-39.

22. Li, J.; Huang, Y.; Huang, J.; Liang, G.; Zhang, Y.; Rey, G.; Guo, F.; Su, Z.; Zhu, H.; Cai, L.; Sun, K.; Sun, Y.; Liu, F.; Chen, S.; Hao, X.; Mai, Y.; Green, M. A., Defect Control for 12.5\% Efficiency $\mathrm{Cu} 2 \mathrm{ZnSnSe} 4$ Kesterite Thin - Film Solar Cells by Engineering of Local Chemical Environment. Advanced materials 2020, 32 (52), 2005268. 
23. Li, J.; Kim, S.; Nam, D.; Liu, X.; Kim, J.; Cheong, H.; Liu, W.; Li, H.; Sun, Y.; Zhang, Y., Tailoring the defects and carrier density for beyond 10\% efficient CZTSe thin film solar cells. Solar Energy Materials and Solar Cells 2017, 159, 447-455.

24. Gong, Y.; Zhang, Y.; Zhu, Q.; Zhou, Y.; Qiu, R.; Niu, C.; Yan, W.; Huang, W.; Xin, H., Identifying the origin of the Voc deficit of kesterite solar cells from the two grain growth mechanisms induced by Sn2+ and Sn4+ precursors in DMSO solution. Energy \& Environmental Science 2021, 14 (4), 2369-2380.

25. Guo, L.; Shi, J.; Yu, Q.; Duan, B.; Xu, X.; Zhou, J.; Wu, J.; Li, Y.; Li, D.; Wu, H.; Luo, Y.; Meng, Q., Coordination engineering of $\mathrm{Cu}-\mathrm{Zn}-\mathrm{Sn}-\mathrm{S}$ aqueous precursor for efficient kesterite solar cells. Science Bulletin 2020, 65 (9), 738-746.

26. Li, J.; Wang, D.; Li, X.; Zeng, Y.; Zhang, Y., Cation Substitution in Earth-Abundant Kesterite Photovoltaic Materials. Adv Sci (Weinh) 2018, 5 (4), 1700744.

27. Shin, D.; Saparov, B.; Mitzi, D. B., Defect Engineering in Multinary Earth-Abundant Chalcogenide Photovoltaic Materials. Advanced Energy Materials 2017, 7 (11), 1602366.

28. Cui, X.; Sun, K.; Huang, J.; Yun, J. S.; Lee, C.-Y.; Yan, C.; Sun, H.; Zhang, Y.; Xue, C.; Eder, K.; Yang, L.; Cairney, J. M.; Seidel, J.; Ekins-Daukes, N. J.; Green, M.; Hoex, B.; Hao, X., CdFree $\mathrm{Cu} 2 \mathrm{ZnSnS} 4$ solar cell with an efficiency greater than $10 \%$ enabled by $\mathrm{A} 12 \mathrm{O} 3$ passivation layers. Energy \& Environmental Science 2019, 12 (9), 2751-2764.

29. Sun, K.; Yan, C.; Huang, J.; Liu, F.; Li, J.; Sun, H.; Zhang, Y.; Cui, X.; Wang, A.; Fang, Z.; Cong, J.; Lai, Y.; Green, M. A.; Hao, X., Beyond 10\% efficiency Cu2ZnSnS4 solar cells enabled by modifying the heterojunction interface chemistry. Journal of Materials Chemistry A 2019, 7 (48), 2728927296.

30. He, M.; Yan, C.; Li, J.; Suryawanshi, M. P.; Kim, J.; Green, M. A.; Hao, X., Kesterite Solar Cells: Insights into Current Strategies and Challenges. Adv Sci (Weinh) 2021, 8 (9), 2004313.

31. Yan, C.; Huang, J.; Sun, K.; Johnston, S.; Zhang, Y.; Sun, H.; Pu, A.; He, M.; Liu, F.; Eder, K.; Yang, L.; Cairney, J. M.; Ekins-Daukes, N. J.; Hameiri, Z.; Stride, J. A.; Chen, S.; Green, M. A.; Hao, X., Cu2ZnSnS4 solar cells with over $10 \%$ power conversion efficiency enabled by heterojunction heat treatment. Nature Energy 2018, 3 (9), 764-772.

32. Su, Z.; Liang, G.; Fan, P.; Luo, J.; Zheng, Z.; Xie, Z.; Wang, W.; Chen, S.; Hu, J.; Wei, Y.; Yan, C.; Huang, J.; Hao, X.; Liu, F., Device Postannealing Enabling over 12\% Efficient SolutionProcessed Cu2 ZnSnS4 Solar Cells with Cd(2+) Substitution. Adv Mater 2020, 32 (32), e2000121.

33. Fonoll-Rubio, R.; Andrade-Arvizu, J.; Blanco-Portals, J.; Becerril-Romero, I.; Guc, M.; Saucedo, E.; Peiró, F.; Calvo-Barrio, L.; Ritzer, M.; Schnohr, C. S.; Placidi, M.; Estradé, S.; IzquierdoRoca, V.; Pérez-Rodríguez, A., Insights into interface and bulk defects in a high efficiency kesterite-based device. Energy \& Environmental Science 2021, 14 (1), 507-523.

34. Vishwakarma, M.; Varandani, D.; Andres, C.; Romanyuk, Y. E.; Haass, S. G.; Tiwari, A. N.; Mehta, B. R., A direct measurement of higher photovoltage at grain boundaries in CdS/ CZTSe solar cells using KPFM technique. Solar Energy Materials and Solar Cells 2018, 183, 34-40.

35. Krause, M.; Nikolaeva, A.; Maiberg, M.; Jackson, P.; Hariskos, D.; Witte, W.; Marquez, J. A.; Levcenko, S.; Unold, T.; Scheer, R.; Abou-Ras, D., Microscopic origins of performance losses in highly efficient $\mathrm{Cu}(\mathrm{In}, \mathrm{Ga}) \mathrm{Se} 2$ thin-film solar cells. Nature communications 2020, 11 (1), 4189.

36. Zhao, Y.; Boccard, M.; Liu, S.; Becker, J.; Zhao, X.-H.; Campbell, C. M.; Suarez, E.; Lassise, M. B.; Holman, Z.; Zhang, Y.-H., Monocrystalline CdTe solar cells with open-circuit voltage over $1 \mathrm{~V}$ and efficiency of 17\%. Nature Energy 2016, 1 (6). 
37. Lee, Y. S.; Gershon, T.; Gunawan, O.; Todorov, T. K.; Gokmen, T.; Virgus, Y.; Guha, S., Cu2ZnSnSe4Thin-Film Solar Cells by Thermal Co-evaporation with $11.6 \%$ Efficiency and Improved Minority Carrier Diffusion Length. Advanced Energy Materials 2015, 5 (7), 1401372.

38. Gunshor, R. L.; Kolodziejski, L. A., Recent advances in the molecular beam epitaxy of the widebandgap semiconductor $\mathrm{ZnSe}$ and its superlattices. IEEE journal of quantum electronics 1988, 24 (8), $1744-1757$.

39. Hages, C. J.; Carter, N. J.; Agrawal, R.; Unold, T., Generalized current-voltage analysis and efficiency limitations in non-ideal solar cells: Case of $\mathrm{Cu} 2 \mathrm{ZnSn}(\mathrm{SxSe} 1-\mathrm{x}) 4$ and $\mathrm{Cu} 2 \mathrm{Zn}(\mathrm{SnyGe1}-\mathrm{y})(\mathrm{SxSe} 1-\mathrm{x}) 4$. Journal of Applied Physics 2014, 115 (23).

40. Roberts, G.; Polanco, J., Thermally assisted tunnelling in dielectric films. physica status solidi (a) 1970, 1 (3), 409-420.

41. Hegedus, S. S.; Shafarman, W. N., Thin-film solar cells: device measurements and analysis. Progress in Photovoltaics: Research and Applications 2004, 12 (23), 155-176.

42. Li, J.; Deng, B.; Zhu, H.; Guo, F.; You, X.; Shen, K.; Wan, M.; Mai, Y., Rear interface modification for efficient $\mathrm{Cu}(\mathrm{In}, \mathrm{Ga}) \mathrm{Se} 2$ solar cells processed with metallic precursors and low-cost $\mathrm{Se}$ vapor. Solar Energy Materials and Solar Cells 2018, 186, 243-253.

43. Wang, K.; Gunawan, O.; Todorov, T.; Shin, B.; Chey, S. J.; Bojarczuk, N. A.; Mitzi, D.; Guha, S., Thermally evaporated Cu2ZnSnS4 solar cells. Applied Physics Letters 2010, 97 (14), 143508.

44. Li, J.; Zhang, Y.; Zhao, W.; Nam, D.; Cheong, H.; Wu, L.; Zhou, Z.; Sun, Y., A Temporary Barrier Effect of the Alloy Layer During Selenization: Tailoring the Thickness of MoSe2for Efficient Cu2ZnSnSe4Solar Cells. Advanced Energy Materials 2015, 5 (9), 1402178.

45. Barkhouse, D. A. R.; Gunawan, O.; Gokmen, T.; Todorov, T. K.; Mitzi, D. B., Device characteristics of a $10.1 \%$ hydrazine-processed $\mathrm{Cu} 2 \mathrm{ZnSn}(\mathrm{Se}, \mathrm{S}) 4$ solar cell. Progress in Photovoltaics: Research and Applications 2012, 20 (1), 6-11.

46. Okimura, H.; Matsumae, T.; Makabe, R. J. T. S. F., Electrical properties of Cu2- xSe thin films and their application for solar cells. 1980, 71 (1), 53-59.

47. Zhao, L.-D.; Tan, G.; Hao, S.; He, J.; Pei, Y.; Chi, H.; Wang, H.; Gong, S.; Xu, H.; Dravid, V. P. J. S., Ultrahigh power factor and thermoelectric performance in hole-doped single-crystal SnSe. 2016, 351 (6269), 141-144.

48. Nichterwitz, M.; Caballero, R.; Kaufmann, C. A.; Schock, H.-W.; Unold, T., Generationdependent charge carrier transport in $\mathrm{Cu}(\mathrm{In}, \mathrm{Ga}) \mathrm{Se} 2 / \mathrm{CdS} / \mathrm{ZnO}$ thin-film solar-cells. Journal of Applied Physics 2013, 113 (4).

49. Nichterwitz, M.; Unold, T., Numerical simulation of cross section electron-beam induced current in thin-film solar-cells for low and high injection conditions. Journal of Applied Physics 2013, 114 (13).

50. Heath, J. T.; Cohen, J. D.; Shafarman, W. N., Bulk and metastable defects in CuIn1-xGaxSe2 thin films using drive-level capacitance profiling. Journal of Applied Physics 2004, 95 (3), 1000-1010.

51. Rau, U.; Werner, J. H., Radiative efficiency limits of solar cells with lateral band-gap fluctuations. Applied Physics Letters 2004, 84 (19), 3735-3737.

52. Schwarz, T.; Cojocaru-Mirédin, O.; Choi, P.; Mousel, M.; Redinger, A.; Siebentritt, S.; Raabe, D., Atom probe tomography study of internal interfaces in Cu2ZnSnSe4 thin-films. Journal of Applied Physics 2015, 118 (9).

53. Cojocaru-Mirédin, O.; Schwarz, T.; Abou-Ras, D., Assessment of elemental distributions at line and planar defects in $\mathrm{Cu}(\mathrm{In}, \mathrm{Ga}) \mathrm{Se} 2$ thin films by atom probe tomography. Scripta Materialia 2018, 148, 106-114.

54. Mendis, B. G.; Bowen, L.; Jiang, Q. Z., A contactless method for measuring the recombination velocity of an individual grain boundary in thin-film photovoltaics. Applied Physics Letters 2010, 97 (9). 
55. Seager, C. H., The determination of grain - boundary recombination rates by scanned spot excitation methods. Journal of Applied Physics 1982, 53 (8), 5968-5971.

56. Gershon, T.; Shin, B.; Bojarczuk, N.; Hopstaken, M.; Mitzi, D. B.; Guha, S., The Role of Sodium as a Surfactant and Suppressor of Non-Radiative Recombination at Internal Surfaces in Cu2ZnSnS4. Advanced Energy Materials 2015, 5 (2), 1400849.

57. Sproul, A. B., Dimensionless solution of the equation describing the effect of surface recombination on carrier decay in semiconductors. Journal of Applied Physics 1994, 76 (5), 2851-2854.

58. Gunawan, O.; Pae, S. R.; Bishop, D. M.; Virgus, Y.; Noh, J. H.; Jeon, N. J.; Lee, Y. S.; Shao, X.; Todorov, T.; Mitzi, D. B.; Shin, B., Carrier-resolved photo-Hall effect. Nature 2019, 575 (7781), 151-155.

59. Tampo, H.; Kim, K. M.; Kim, S.; Shibata, H.; Niki, S., Improvement of minority carrier lifetime and conversion efficiency by $\mathrm{Na}$ incorporation in $\mathrm{Cu} 2 \mathrm{ZnSnSe} 4$ solar cells. Journal of Applied Physics 2017, 122 (2), 023106.

60. Bass, J. J. A. i. P., Deviations from Matthiessen's rule. Advances in Physics 1972, 21 (91), 431604.

61. Lloyd, M. A.; Ma, X.; Kuba, A. G.; McCandless, B. E.; Doty, M. F.; Birkmire, R., Effects of composition and thermal treatment on $\mathrm{V}_{\mathrm{OC}}$ - limiting defects in single - crystalline $\mathrm{Cu}_{2} \mathrm{ZnSnSe}_{4}$ solar cells. Progress in Photovoltaics: Research and Applications 2021.

62. Metzger, W. K.; Grover, S.; Lu, D.; Colegrove, E.; Moseley, J.; Perkins, C. L.; Li, X.; Mallick, R.; Zhang, W.; Malik, R.; Kephart, J.; Jiang, C. S.; Kuciauskas, D.; Albin, D. S.; Al-Jassim, M. M.; Xiong, G.; Gloeckler, M., Exceeding 20\% efficiency with in situ group V doping in polycrystalline CdTe solar cells. Nature Energy 2019, 4 (10), 837-845.

63. Li, J.; Huang, J.; Huang, Y.; Tampo, H.; Sakurai, T.; Chen, C.; Sun, K.; Yan, C.; Cui, X.; Mai, Y.; Hao, X., Interface Recombination of Cu2ZnSnS4 Solar Cells Leveraged by High Carrier Density and Interface Defects. Solar RRL 2021, 5 (10).

64. Li, J.; Wang, H.; Wu, L.; Chen, C.; Zhou, Z.; Liu, F.; Sun, Y.; Han, J.; Zhang, Y., Growth of $\mathrm{Cu} 2 \mathrm{ZnSnSe} 4$ Film under Controllable Se Vapor Composition and Impact of Low Cu Content on Solar Cell Efficiency. ACS applied materials \& interfaces 2016, 8 (16), 10283-92.

65. Drouin, D.; Couture, A. R.; Joly, D.; Tastet, X.; Aimez, V.; Gauvin, R., CASINO V2. 42-a fast and easy - to - use modeling tool for scanning electron microscopy and microanalysis users. Scanning: The Journal of Scanning Microscopies 2007, 29 (3), 92-101.

66. Pu, A.; Ma, F.; Yan, C.; Huang, J.; Sun, K.; Green, M.; Hao, X., Sentaurus modelling of 6.9\% $\mathrm{Cu} 2 \mathrm{ZnSnS} 4$ device based on comprehensive electrical \& optical characterization. Solar Energy Materials and Solar Cells 2017, 160, 372-381.

67. Jones, G.; Woods, J., The electrical properties of zinc selenide. Journal of Physics D: Applied Physics 1976, 9 (5), 799.

68. El Otmani, R.; El Manouni, A.; Al Maggoussi, A., Numerical Simulation of CZTSe Based Solar Cells Using Different Back Surface Field Layers: Improvement and Comparison. Journal of Electronic Materials 2021, 50 (4), 2021-2033. 


\section{Supplementary Files}

This is a list of supplementary files associated with this preprint. Click to download.

- supportinginformation.pdf 